\title{
Atrial Tachycardia With AV Block by ECG Finding
}

National Cancer Institute

\section{Source}

National Cancer Institute. Atrial Tachycardia With AV Block by ECG Finding. NCI

Thesaurus. Code C119249.

An electrocardiographic recording that demonstrates atrial tachycardia without 1:1 atrioventricular conduction. 